\title{
MANAGING THE EARLY PHASE OF REHABILITATION AFTER ISCHEMIC CEREBROVASCULAR
} ACCIDENT

\author{
EQREM GARA, BEKIM HAXHIU, ZHERALLDIN DURGUTI, ARDIANA MURTEZANI* \\ Physical Medicine and Rehabilitation Clinic, University of Pristina, Kosovo \\ Email: ardianaa@yahoo.com
}

Received: 07 Mar 2017 Revised and Accepted: 09 May 2017

\begin{abstract}
Objective: Ischemic cerebrovascular accident (ICA) is characterised by the rapid deterioration of brain function due to vascularization disorders. The ischemic cerebrovascular accident may arise as a consequence of ischemia or hemhorrage in brain tissue, but the optimal treatment approach is unclear. In this study, we examined ICA rehabilitation goals, implementation of rehabilitation plans, management of sensomotor deficits and functional status, improvement of independence, prevention and treatment of complications, functional status monitoring, and planning recommendations, as well as education of ICA patients and their families.
\end{abstract}

Methods: This study considered 69 ICA patients who were classified as suitable for rehabilitation intervention among a total of 231 patients who were evaluated for a diagnosis of ICA following hospitalization at the Clinic of Neurology, University Clinical Center of Kosovo (UCCK) in Prishtina. From the statistical parameters, we used the structure index, whereas testing results were evaluated using the Chi-square test with significance established at $\mathrm{p}<0.05$.

Results: For the 69 ICA patients, most ICA incidents occurred in patients who were older than 40 y-old. Mobility decreased from $42.9 \%$ to $8.6 \%$ when rehabilitation began at release instead of admission. Meanwhile, the ability to perform daily activities decreased from $48.6 \%$ to $11.4 \%$ when rehabilitation began after release as opposed to immediately after stabilization. Transfers and balance showed similar decreases $(48.6 \%$ to $11.4 \%$ and $48.6 \%$ to $11.4 \%$, respectively Chi-test=59.7, $\mathrm{p}<0.001$.). The rehabilitation of patients in the early acute stage after ICA should begin as soon as possible after the diagnosis is made and the patient's condition is stable. During rehabilitation intervention, priority should be given to preventing complications and recurrent stroke, as well as enhancing patient mobility and improving patient morale.

Conclusion: ICA is a medical emergency that can cause permanent neurological lesions and other complications that may be fatal or associated with permanent disability. The most affected age group is individuals older than $40 \mathrm{y}$ old. Neurological deficits can cause motor, sensory, functional and emotional disability in ICA patients. Rehabilitation after ICA should begin immediately after the patient has stabilized to minimze functional losses.

Keywords: ICA (Ischemic Cerebrovascular Accident), Hemorrhagic, Early phase, Rehabilitation

(C) 2017 The Authors. Published by Innovare Academic Sciences Pvt Ltd. This is an open access article under the CC BY license (http://creativecommons.org/licenses/by/4.0/) DOI: http://dx.doi.org/10.22159/ijpps.2017v9i6.18345

\section{INTRODUCTION}

Ischemic cerebrovascular stroke (ICA) is characterized by rapid deterioration of brain function due to vascular disorders. ICA may arise as a consequence of ischemia or hemorrhage in brain tissue [1]. The resulting brain damage can result in difficulties moving one side of the body, or cognitive deficits manifested as difficulty understanding words or speaking [2]. Risk factors associated with ICA include older age, arterial hypertension, diabetes, high cholesterol levels, smoking and atrial fibrillation [2].

ICA can occur at any age during adulthood, but the incidence increases above the age of 30 [3]. Nealy all (95\%) ICAs occur in individuals who are older than $45 \mathrm{y}$ or age, and $2 / 3$ of cases present in individuals older than 65 [4]. Males have a 25\% higher risk of ICA relative to females[4], but mortality rates are higher for women [5].

ICAs can be classified into two major categories: ischemic and hemorrhagic [6]. The former is more common and represents around $87 \%$ of all strokes. Those strokes that present without a known cause are referred to as cryptogenic and account for between 30 and $40 \%$ of ischemic strokes [2, 7].

Symptoms of ICA typically emerge suddenly and last between a few seconds and several minutes, and in most cases do not progress beyond this time period. The symptoms that manifest after ICA depend on the region of the brain that is affected and larger areas of brain tissue damage result in more pronounced sympotoms and functional loss [7]. In most cases, ICA symptoms affect one side of the body, which is referred to as hemiparesis or unilateral hemiplegia $[8,9]$.
This study sought to determine the goals of rehabilitation, the implementation of rehabilitation plans and approaches to managing sensomotor deficits and functional status, as well as methods for improving independence, preventing and treating complications, functional status monitoring, delivery of recommendations, and education of ICA patients and their families.

\section{MATERIALS AND METHODS}

This study assessed 69 ICA patients who were among 231 ICA patients given a diagnosis of a cerebrovascular stroke upon hospitalization at the Clinic of Neurology, UCCK-Pristina. The 69 patients were judged to be suitable for rehabilitation intervention. All patients were examined and diagnosed at the Clinic of Neurology, UCCK in Pristina. Patient data collected included general information (name, age, gender, address), history (when the stroke occurred, examinations by relevant specialists), disease etiology, diagnosis, complications accompanying neurological problems, a list of problems, and a list of treatments received.

During the functional status examination, these parameters are observed (analyzed): upper and lower extremities range of motion of the affected side, manual test examination for the muscular strength of the affected side, extremities perimeter measurement, tendon reflex examination, evaluation of motion coordination, positional mobility, and balance.

\section{Statistical analysis}

Statistical parameters were analyzed using a structure index, whereas testing results were analyzed by a Chi-square test. Results were considered to differ significantly at $\mathrm{p}<0.05$. 


\section{Ethical approval}

The study design, protocols, procedures and informed consent form were approved by the Medical Ethic Committee, University Clinical Center of Kosovo, Prishtina, Kosovo, no 6/1978.

\section{RESULTS}

Of a total of 231 ICA cases, 69 had stabilized and subsequently underwent initial physiotherapy intervention. The patients were hospitalized in the Clinic of Neurology, UCCK, and came from all regions of Kosovo.

ICA patients between 40 and $60 \mathrm{y}$ old had the highest percentage of individuals who had sufficient stability to undergo rehabilitation (53.6\%; table 2). Meanwhile, $43.5 \%$ of ICA patients suitable for rehabilitation were older than 60 . There were no significant differences observed with respect to gender (Chi test=2.7, $\mathrm{p}<0.3$ ).

Table 1: Condition before rehabilitation by gender

\begin{tabular}{|c|c|c|c|c|c|c|}
\hline \multirow[t]{3}{*}{ Condition } & \multicolumn{4}{|c|}{ Gender } & \multirow{2}{*}{\multicolumn{2}{|c|}{ Total $(n=231)$}} \\
\hline & \multicolumn{2}{|c|}{ Female $(n=96)$} & \multicolumn{2}{|c|}{ Male (n=135) } & & \\
\hline & No. & $(\%)$ & No. & (\%) & No. & $(\%)$ \\
\hline Stable & 30 & 31.3 & 39 & 28.9 & 69 & 29.9 \\
\hline Average stable & 37 & 38.5 & 55 & 40 & 92 & 39.8 \\
\hline Unstable & 29 & 30.2 & 41 & 30.4 & 70 & 30.3 \\
\hline Total & 96 & 100.0 & 135 & 100.0 & 231 & 100.0 \\
\hline
\end{tabular}

Table 2: Ages and genders of stable ICA cases eligible for rehabilitation

\begin{tabular}{|c|c|c|c|c|c|c|}
\hline \multirow[t]{3}{*}{ Age (y-old) } & \multicolumn{4}{|c|}{ Gender } & \multirow{2}{*}{\multicolumn{2}{|c|}{ Total }} \\
\hline & \multicolumn{2}{|c|}{ Female } & \multicolumn{2}{|c|}{ Male } & & \\
\hline & No. & $(\%)$ & No. & $(\%)$ & No. & (\%) \\
\hline$<40$ & 2 & 6.7 & 0 & 0.0 & 2 & 2.9 \\
\hline $40-60$ & 15 & 50.0 & 22 & 56.4 & 37 & 53.6 \\
\hline$>61$ & 13 & 43.3 & 17 & 43.6 & 30 & 43.5 \\
\hline Total & 30 & 100.0 & 39 & 100.0 & 69 & 100.0 \\
\hline
\end{tabular}

Among those patients who presented with arm pain of varying degrees and hemiparesis, most patients (58 cases, 82.6\%) had low- intensity pain, whereas 11 cases experienced high-intensity pain (17.4\%, table 3).

Table 3: Distribution of ICA patients with arm pain and hemiparesis according to affected side and gender

\begin{tabular}{|c|c|c|c|c|c|c|c|}
\hline \multirow[t]{3}{*}{ Affected side } & \multirow[t]{3}{*}{ Pain } & \multicolumn{4}{|c|}{ Gender } & \multirow{2}{*}{\multicolumn{2}{|c|}{ Total }} \\
\hline & & \multicolumn{2}{|c|}{ Female } & \multicolumn{2}{|c|}{ Male } & & \\
\hline & & No. & $(\%)$ & No. & (\%) & No. & $(\%)$ \\
\hline \multirow[t]{3}{*}{ Right side } & Low & 12 & 40.0 & 15 & 38.5 & 27 & 39.1 \\
\hline & Strong & 2 & 6.7 & 3 & 7.7 & 5 & 7.2 \\
\hline & Total & 14 & 46.7 & 18 & 46.2 & 32 & 46.4 \\
\hline \multirow[t]{3}{*}{ Left side } & Low & 14 & 46.7 & 17 & 43.6 & 31 & 44.9 \\
\hline & Strong & 2 & 6.7 & 4 & 10.3 & 6 & 8.7 \\
\hline & Total & 16 & 53.3 & 21 & 53.8 & 37 & 53.6 \\
\hline Total & & 30 & 100.0 & 39 & 100.0 & 69 & 100.0 \\
\hline
\end{tabular}

The stage when rehabilitation began affected mobility in that ICA patient who began rehabilitation upon release had significantly lower mobility than those patients who began at admission $(8.6 \%$ vs. $42.9 \%$; table 4 ). The ability to perform daily activities, transfer from a bed to a chair and balance showed similar differences depending on whether rehabilitation began at admission or upon release $(48.6 \%$ and $11.4 \%, 48.6$ and $11.4 \%$, and $48.6 \%$ and $11.4 \%$, respectively; Chi-test $=59.7, \mathrm{p}<0.001$; table 4 ).

Table 4: Distribution of patients with arm pain and hemiparesis according to gender and treatment stage

\begin{tabular}{|c|c|c|c|c|c|}
\hline \multirow[t]{3}{*}{ Neurologic status } & \multirow[t]{3}{*}{ Pain } & \multicolumn{4}{|c|}{ Gender } \\
\hline & & \multicolumn{2}{|c|}{ Female $(n=96)$} & \multicolumn{2}{|c|}{ Male $(n=135)$} \\
\hline & & No. & (\%) & No. & (\%) \\
\hline \multirow[t]{3}{*}{ Mobility possibiity } & Admission & 11 & 11.5 & 15 & 42.9 \\
\hline & Release & 24 & 25.0 & 3 & 8.6 \\
\hline & Total & 35 & 36.5 & 18 & 51.4 \\
\hline \multirow[t]{3}{*}{ Activities of daily living } & Admission & 10 & 10.4 & 17 & 48.6 \\
\hline & Release & 22 & 22.9 & 4 & 11.4 \\
\hline & Total & 32 & 33.3 & 21 & 60.0 \\
\hline \multirow[t]{3}{*}{ Transfers } & Admission & 8 & 8.3 & 17 & 48.6 \\
\hline & Release & 26 & 27.1 & 4 & 11.4 \\
\hline & Total & 34 & 35.4 & 21 & 60.0 \\
\hline \multirow[t]{3}{*}{ Balance } & Admission & 5 & 5.2 & 17 & 48.6 \\
\hline & Release & 18 & 18.8 & 4 & 11.4 \\
\hline & Total & 23 & 24.0 & 21 & 60.0 \\
\hline
\end{tabular}

Results of the study were presented in tables. From the statistical parameters, we used a structure index, whereas testing results were evaluated using the Chi-square test with $\mathrm{p}<0.05$ considered as significant. 


\section{DISCUSSION}

The study seeks to show the complexity of cerebrovascular stroke by determining complications associated with stroke and how these complications depend on etiology, gender, and ICA type. Moreover, we examined how the complications were associated with ICA patient stability and physiotherapy regimen and complexity during the acute phases and early stages of rehabilitation after ICA. Over the years, the organisation of rehabilitation interventions has changed in quality and form in response to the evolution of rehabilitative medicine, as well as the development of physiotherapy and ergotherapy techniques. Our study examined a population of ICA patients in Kosovo. We found that ICA was most frequent in patients who were over age 60 (57.8\% of cases), although this difference was not significant compared to the rate for ICA patients between 40 and $60 \mathrm{y}$-old, who represented $42.2 \%$ of cases. We observed no gender differences in ICA frequency. (Chi test=5.0, $\mathrm{p}<0.08$ ). More than $75 \%$ of ICA patients experienced some degree of disability that affected their ability to work. Similarly, hemiparesis affected $75 \%$ of ICA patients who were enrolled in the study. The ICA symptoms typically had a sudden and unexpected onset and lasted for a few seconds or minutes, and in most cases did not progress this time period. The symptoms manifested after the ICA depended on which area of the brain was involved. The larger the area that was involved, the more pronounced the symptoms and accompanying functional losses. As noted earlier, rehabilitation of ICA patients in the early acute stage should begin rehabilitation as soon as possible after diagnosis and when their condition has stabilized [10-14]. During rehabilitation interventions, priority should be given to prevention of complications and recurrent stroke, as well as enhancing patient mobility and morale $[11,12]$. In our study, 69 patients had sufficient stability to begin rehabilitation and there were no significant differences in patient numbers with respect to gender (Chi-test $=0.2, p<0.9$ ). Younger patients were more likely to have attained the necessary stability to begin rehabilitation, wherein $53.6 \%$ of ICA patients suitable to begin rehabilitation were between 40 and $60 \mathrm{y}$-old and $43.5 \%$ of patients that could start rehabilitation were older than 60 . Again, there were no significant differences between gender (table 2; Chi test $=2.7, p<0.3$ ). A total of 32 and 37 ICA patients had right and left side hemiparesis, respectively ( $46.5 \%$ and $53.5 \%$ of cases; table 3 ). There were no significant differences in terms of affected side and gender gap (Chi test $=0: 04, p<0.8)$. Numerous studies demonstrated that the majority of stroke patients $(70 \%-84 \%)$ experienced low-intensity pain in the humeroscapular region and upper extremity paralysis. Notably, glenohumeral articulation is very vulnerable to effects of ICA because it sacrifices stability in favor of the movement. In the flaccid phase after ICA, the force of gravity alone can result in an extension of the capsule that can later manifest as "frozen shoulder" and symptoms accompanying this condition, including pain, restriction of mobility, and functional deficit [15]. As such, prevention of complications in the humeroscapular region should begin during the early phase of ICA patient rehabilitation $[16,17]$. Such preventative measures can include adequate positioning with a normal scapularhumeral orientation, as well as avoiding lifting and transfers of patients that involve the shoulder region. Furthermore, mobilization of this region should not exceed 90 degrees of flexion or abduction. The use of orthosis support is controversial because of possible complications that can arise due to the immobilization. In our study, $58(82.6 \%)$ of ICA patients experienced low-intensity pain whereas 11 cases $(17.4 \%)$ of cases had high-intensity pain; there were no significant differences with respect to gender. Mobilization of ICA patients is recommended as soon as the patient's health and neurological conditions allow-preferably $24-48 \mathrm{~h}$ after admission $[18,19]$. Frequent shifts in position, transfers in the bed, passive and active mobilization of the affected extremities and those of the healthy side should be part of patient care from the moment of hospitalization. Proper positioning also helps prevent aspiration, decubitus, articular contraction, edema and deep venous thrombosis $[20,21]$. Assessment of mobility begins with an evaluation of the ability of the patient to be transferred from one side to the other, the patient's ability to sit on a couch, and then progresses to assess the patient's ability to sit on the edge of bed. Upon reaching these goals, the assessment continues to gauge the ability of the patient to transfer to a simple chair, maintain an upright position, and, finally, the ability to stand upright and walk [22-25]. Determining a proper sitting position depends on the ability to balance in a seated position and muscular endurance. Transfers in bed, to a chair and to a standing posture should be taught by a physiotherapist to both the patient and family members and be applied during patient mobilization [26-28]. In our study, the effect of early rehabilitation for ICA patients showed that the possibility of mobility decreased from $42.9 \%$ to $8.6 \%$ between admission and release, whereas the ability to perform daily activities decreased from $48.6 \%$ to $11.4 \%$. Meanwhile, transfers and balance also decreased between admission and release ( 48.6 to $11.4 \%$ and $48.6 \%$ to $11.4 \%$, respectively; Chitest=59.7, $\mathrm{p}<0.001$ ).

A few limitations should be noted. The main weakness relates to the duration of the study. Long term outcomes were not performed on these subjects so it cannot be determined if the effect of treatment can be maintained over time. Another disadvantage is that psychological factors were not addressed and thus their potential influence on rehabilitation could not be established.

\section{CONCLUSION}

ICA is a medical emergency that can cause permanent neurological lesions and other complications that can be fatal or result in permanent disability. Ischemic strokes are significantly more frequent than hemorrhagic strokes, and typically affect individuals who are more than $40 \mathrm{y}$-old. Neurological deficits induced by stroke can affect motor skills and sensory perception, as well as promote functional and emotional disabilities. The seriousness of the neurological deficit significantly affects the success of rehabilitation for ICA patients. Supervised rehabilitation interventions for ICA patients should begin as soon after diagnosis as possible. In Kosovo, the majority of patients in the early stage of rehabilitation had either a stable or average stable condition. Patients with the unstable condition should undergo proper positioning and other measures to prevent possible complications due to inactivity.

\section{ACKNOWLEDGMENT}

We would like to thank all the patients who participated in this study without laziness.

\section{AUTHORS` CONTRIBUTION}

All authors contributed equally in the preparation of the manuscript.

Gara and Murtezani were overseeing this project, had full access and responsibility of the data.

Study Design: Gara, Murtezani and Haxhiu.

Instruction on the use of instruments for the outcome measures used in this study: Gara, Murtezani and Durguti.

Analysis and interpretation of data: Murtezani and Durguti.

Manuscript preparation: Gara and Murtezani

Statistical Analysis: Murtezani, Gara and Haxhiu.

\section{CONFLICT OF INTERESTS}

\section{Declared none}

\section{REFERENCES}

1. Sims NR, Muyderman H. Mitochondria, oxidative metabolism and cell death in stroke. Biochim Biophys Acta 2009; 1802:80-91.

2. Donnan GA, Fisher M, Macleod M, Davis SM. Stroke. Lancet 2008;371:1612-23.

3. The World health report 2004. Annex table 2: Deaths by cause, sex and mortality stratum in WHO regions, estimates for 2002. Geneva: World Health Organization; 2004.

4. Nor AM, Davis J, Sen B, Shipsey D, Louw SJ, Dyker AG, et al. The recognition of stroke in the emergency room (ROSIER) scale: development and validation of a stroke recognition instrument. Lancet Neurol 2005;4:727-34. 
5. Coffey CE, Cummings JL, Starkstein S, Robinson R. Stroke-the American psychiatric press textbook of geriatric neuropsychiatry. 2en ed. Washington DC: American Psychiatric Press; 2000. p. 601-17.

6. Kidwell CS, Warach S. Acute ischemic cerebrovascular syndrome: diagnostic criteria. Stroke 2003;34:2995-8.

7. Stam J. Thrombosis of the cerebral veins and sinuses. New England J Med 2005;352:1791-8.

8. Vakati HS, Jebakumar R. Predicting ratings for user reviews and opinion mining analyze for physicians and hospitals. Asian J Pharm Clin Res 2017;10:47-9.

9. Patil N, Balaji O, Rao KN, Hande HM, Ahmed T, Singhal S. A rare cause of septic arthritis with pleural effusion: Burkholderia pseudomallei. Asian J Pharm Clin Res 2017;10:8-9.

10. Gresham GE, Duncan PW, Stason WB, Adams HP, Adelman AM, Alexander DN, et al. Post-stroke rehabilitation: assessment, referral, and patient management: Quick reference guide for clinicians. J Pain Symptom Manage 1996;4:57-95.

11. Bushnell CD, Johnston DC, Goldstein LB. Retrospective assessment of initial stroke severity: comparison of the NIH stroke scale and the canadian neurological scale. Stroke 2001;32:656-60.

12. Duncan PW, Lai SM, Van CV, Huang L, Clausen D, Wallace D. Development of a comprehensive assessment toolbox for stroke. Clin Geriatr Med 1999;15:885-915.

13. Roe B, Williams $\mathrm{K}$, Palmer $\mathrm{M}$. Bladder training for urinary incontinence in adults. Cochrane Database Syst Rev 2000;2:CD001308.

14. Mahmudah RL, Ikawati Z, Wahyono D. A qualitative study of perspectives, expectations and needs of education in chronic obstructive pulmonary disease (Copd). Int J Curr Pharm Res 2017;9:32-5.

15. Indredavik B, Bakke F, Solberg R, Rokseth $R$, Haaheim LL, Holme I. Benefit of a stroke unit: a randomized controlled trial. Stroke 1991;22:1026-31.

16. Smith DS, Goldenberg E, Ashburn A, Kinsella G, Sheikh K, Brennan PJ, et al. Remedial therapy after stroke: a randomised controlled trial. Br Med J 1981;282:517-20.

17. Price CI, Pandyan AD. Electrical stimulation for preventing and treating post-stroke shoulder pain: a systematic cochrane review. Clin Rehabil 2001;15:5-19.
18. Tanguay T, Eichorst C. The braden scale: is your patient at risk for pressure ulcers? Alta RN 2000;56:24-25.

19. Lawton MP, Moss M, Fulcomer M, Kleban MH. A research and service oriented multilevel assessment instrument. J Gerontol 1982;37:91-9.

20. Berlowitz DR, Brandeis GH, Anderson JJ, Ash AS, Kader B, Morris JN, et al. Evaluation of a risk-adjustment model for pressure ulcer development using the minimum data set. J Am Geriatr Soc 2001;49:872-6.

21. Publications committee for the trial of ORG 10172 in acute stroke treatment (TOAST) investigators. low molecular weight heparinoid, ORG 10172 (danaparoid), and outcome after acute ischemic stroke: a randomized controlled trial. The publications committee for the trial of ORG 10172 in acute stroke treatment (TOAST) investigators. JAMA 1998; 279: 1265-72.

22. Kwakkel G, Wagenaar RC, Twisk JW, Lankhorst GJ, Koetsier JC. The intensity of leg and arm training after primary middle-cerebralartery stroke: a randomised trial. Lancet 1999;354:191-6.

23. Early Supported Discharge Trialists. Services for reducing duration of hospital care for acute stroke patients. Cochrane Database Syst Rev 2005;18:CD000443.

24. Rimmer JH, Riley B, Creviston T, Nicola T. Exercise training in a predominantly African-American group of stroke survivors. Med Sci Sports Exercise 2000;32:1990-6.

25. Wojkowski S, Smith J, Richardson J, Birch S, Boyle M. A scoping review of need and unmet need for community-based physiotherapy in Canada. J Crit Rev 2016;3:17-23.

26. Indredavik B, Bakke F, Slordahl SA, Rokseth R, Haheim LL. Stroke unit treatment improves long-term quality of life: a randomized controlled trial. Stroke 1998;29:895-9.

27. Langhorne $P$, Wagenaar $R$, Partridge C. Physiotherapy after stroke: more is better? Physiother Res Int 1996;1:75-88.

28. Sutari RC, Kalaichelvan VK. Evaluation activity of leaf extracts of holoptelea integrifolia (Roxb) planch. Int J Appl Pharm 2014;6:6-8.

\section{How to cite this article}

- $\quad$ Eqrem Gara, Bekim Haxhiu, Zherald Dergut, Ardiana Murtezani. Managing the early phase of rehabilitation after an ischemic cerebrovascular accident. Int J Pharm Pharm Sci 2017;9(6):194-197. 